\title{
The clinical features, management, and survival of elderly patients with colorectal cancer
}

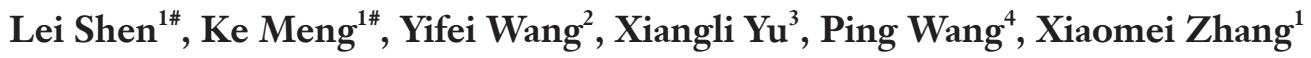 \\ ${ }^{1}$ Department of Gastroenterology, the First Medical Center of PLA General Hospital, Beijing, China; ${ }^{2}$ Medical Big-data Research Center, Medical \\ Innovation Research Division, PLA General Hospital, Beijing, China; ${ }^{3}$ Outpatient Department, the First Medical Center of PLA General Hospital, \\ Beijing, China; ${ }^{4}$ Department of Respiratory and Critical Care Medicine, the Eighth Medical Center of PLA General Hospital, Beijing, China \\ Contributions: (I) Conception and design: X Zhang; (II) Administrative support: P Wang; (III) Provision of study materials or patients: L Shen, K \\ Meng; (IV) Collection and assembly of data: X Yu; (V) Data analysis and interpretation: Y Wang; (VI) Manuscript writing: All authors; (VII) Final \\ approval of manuscript: All authors. \\ \#These authors contributed equally to this work. \\ Correspondence to: Ping Wang. Department of Respiratory and Critical Care Medicine, the Eighth Medical Center of PLA General Hospital, Beijing, \\ China; Email: taoybs_wp@163.com; Xiaomei Zhang. Department of Gastroenterology department, the First Medical Center of PLA General \\ Hospital, Beijing, China. Email: zhangxiaomei@301hospital.com.cn.
}

Background: As the population ages, the number of elderly patients with colorectal cancer is increasing year by year. However, older people have rarely been the focus of studies on colorectal cancer. Therefore, in the present study, we aimed to carry out a retrospective analysis of this patient subgroup.

Methods: A retrospective study of clinical data of patients aged over 80 years who died from colorectal cancer in our hospital between 1993 and 2020 was performed. Logistic regression, the Kaplan-Meier method, and a multivariate Cox proportional hazards model were used to analyze the overall survival and treatment outcomes of the patients.

Results: A total of 87 patients were included in the study. The overall median survival was 45 months. In most patients, the primary lesion was located in the right colon. One-quarter of the patients refused to accept any treatment. Patients with stage IV tumors, who accounted for the largest proportion of the study population, displayed a higher rate of abandoning treatment than did patients of other stages. Almost all patients with stages II and III accepted surgery. Patients who underwent surgery to treat their colorectal cancer had longer survival than those who did not.

Conclusions: Old age should not be a reason for giving up treatment for colorectal cancer. The treatment of colorectal cancer patients aged 80 years and above requires individualized evaluation and more aggressive treatment to achieve greater benefits.

Keywords: Colorectal cancer; elderly; patient; survival analysis; therapy

Submitted Jan 14, 2021. Accepted for publication Feb 08, 2021.

doi: 10.21037/jgo-21-63

View this article at: http://dx.doi.org/10.21037/jgo-21-63

\section{Introduction}

There is no doubt that the Coronavirus Disease 2019 (COVID-19) pandemic leading to a delay of diagnosis and poor care for cancer patients (1). In response to the COVID-19 pandemic, multigastroenterological society guidelines advised all hospitals and outpatient care centers to defer non-emergency medical procedures and surgeries (2), which led to the suspension of screening and monitoring for CRC with colonoscopy. Disruption of colorectal prevention may lead to delayed diagnosis of CRC, tumors were detected at more advanced stage (3). A survey in UK estimates that the number of avoidable cancer deaths will expected increase significantly as a result 
of delayed diagnosis caused by the COVID-19 pandemic. Five years after CRC diagnosed, the number of deaths will increased by $15.3-16.6 \%$, amounting to 1,445 (95\% CI: $1,392-1,591)$ to $1,563(1,534-1,592)$ additional deaths (4). The number of patients aged $>75$ years (i.e., patients who were not invited for biennial fecal immunochemical testing) diagnosed as CRC was significantly lower than expected during the COVID-19 pandemic (5). Cancer patients have been greatly affected by this epidemic.

Colorectal cancer (CRC) ranks as the third most common malignant tumor globally, and it also has the fourth highest mortality rate of any cancer $(6,7)$. By 2035, deaths from colon and rectal cancer are predicted to increase by $60.0 \%$ and $71.5 \%$, respectively, in all countries due to population growth and aging (7). In China, the incidence of CRC has shown a steady incline in recent years (8); from being the $29^{\text {th }}$ leading cause of death in 1990 , by 2017 , the malignancy had risen to $15^{\text {th }}$ place (9). In particular, with the aging of the Chinese population, there has been an increasing number of elderly people receiving diagnoses of colon cancer. However, this group of patients is often overlooked by prospective randomized controlled studies due to the predisposition of elderly patients to multiple underlying diseases. Many studies revealed the features of CRC in elderly patents are quite different from those in the young group. Family syndrome accounts for about $20 \%$ of young-onset colorectal cancers, and the rest are usually microsatellite stable cancers. Early-onset CRC of young adults are characterized by late diagnosis, poorly cell differentiation, and a high incidence of signet ring cell histology, and the primary tumor on the left side of the colon (10). On the contrary, the proportion of rightsided colon cancer and the incidence of microsatellite instability were higher in elderly than in younger colorectal patients (11). There is lack of concrete date on the proportion of family syndrome and microsatellite stable cancer in elderly CRC patient. Elderly patients are more likely to have comorbidities than younger ones, such as cardiovascular disease, respiratory disease, renal insufficiency and liver insufficiency, which increase the risk of treatment. Age is an independent risk factor for hospital morbidity and mortality after colorectal surgery (12). Mucinous carcinoma and serrated adenocarcinoma are likely to be found in elderly CRC patients (13). Elderly patients are more likely to have larger, locally infiltrating CRC, but the frequency of lymph node metastasis is lower than younger patients (14). However, compared with younger patients, elderly CRC patients are undertreated primarily because of their age, not because of their tumor type or comorbidities. The tumor-specific survival time was significantly shorter in elderly patients, partly due to inadequate treatment (15). Moreover, due to the influence of traditional concepts and a lack of confidence in their own health status, elderly patients are prone to give up treatment. So far, no study has specifically focused on different treatment options for this patient group, and data at the high evidence-based medicine level are lacking.

A number of studies have demonstrated that patient survival can be significantly prolonged by endoscopic or surgical resection of the primary lesions, and modes of treatment such as adjuvant chemotherapy and radiotherapy (16). However, there is still a lack of relevant studies on the treatment and prognosis of CRC in elderly patients over the age of 80 years. Physical health varies widely among the elderly population: some individuals are as healthy as younger adults, whereas others suffer from multiple complications and have significantly reduced tolerance to cancer treatment. Whether surgery can obtain benefits and whether adjuvant therapy, such as chemotherapy and radiotherapy, is recommendable are still points of contention in the treatment of CRC patients aged 80 and above. Furthermore, related studies sometimes produce distinct conclusions. As a result, a standardized treatment method for this subgroup does not exist, and treatment decisions are sometimes made according to the wishes of the patients and their families, or the preferences of the treating physician. Many studies underlined the importance of aggressive treatment for patents of CRC. However the majority of them were conducted on patients younger than 80 years. We compared the overall survival time of different treatment in the very old group, which has seldom been provided in previous studies.

In the present study, a retrospective analysis of clinical data of patients aged 80 years and over who died from CRC in PLA General Hospital from 1993 to 2020 was conducted. Using a statistical approach, we assessed the treatment and prognosis of these patients, with the aim of providing clinicians with treatment options for CRC in the elderly population.

We present the following article in accordance with the STROBE reporting checklist (available at http://dx.doi. org/10.21037/jgo-21-63).

\section{Methods}

The study was approved by the PLA General Hospital 
Medical Ethics Committee (No. S2020-447-01). Clinical data of patients aged over 80 years old who were diagnosed with and died from CRC between 1993 and 2020 were retrospectively collected from our hospital records. All patients had a histological diagnosis of CRC. Patients with hereditary CRC based on the medical records were excluded. Patients who were not confirmed by pathology and those whose deaths were not confirmed on their records were excluded, as were patients with incomplete clinical data. All patients were staged according to the American Joint Committee on Cancer/Union for International Cancer Control staging system [tumor-node-metastasis (TNM) staging system] ( $8^{\text {th }}$ edition) (17). For patients without pathological staging data, the clinical stage was used.

\section{Data collection}

Data of cases were collected, including clinical pathology [e.g., (adenocarcinoma, mucinous adenocarcinoma, or adenosquamous carcinoma), degree of differentiation (well, moderately, or poorly differentiated)], clinical stage (stage I, II, III, or IV), anatomic sites (right side of the colon including the cecum, ascending colon, and hepatic flexure; left side of the colon including the splenic flexure, descending colon, sigmoid colon, and rectosigmoid; or the rectum), and clinical features such as age, sex, smoking history, tumor history, and complications.

To minimize the deviation, we selected data from deceased patients. We attached great importance to the integrity of the data, every piece of information is rigorously examined and verified. Special attention was paid to the uniformity of diagnostic criteria for individual cases. A complete pathology report is required for every case. The study subjects were from the same hospital, and the conditions of examination and treatment were consistent. Data were collected by gastroenterology clinicians with 10 years of specialized experience.

All procedures performed in this study involving human participants were in accordance with the Declaration of Helsinki (as revised in 2013). Individual consent for this retrospective analysis was waived.

\section{Statistical analyses}

SAS 9.4 (SAS Institute Inc., Cary, NC, USA) was used for descriptive statistical analysis of the experimental data, and Graphpad prism (GraphPad Software, La Jolla California,
USA) 8.0 was used for the survival analysis. Frequencies (\%) were used to describe enumeration data, and measurement data were described as means, medians, and standard deviations. For survival analysis, univariate Kaplan-Meier analysis and the logrank test were used to draw survival analysis curves. Subsequently, variables with a $\mathrm{P}$ value $<0.05$ in the univariate test were included in a multivariate Cox regression model. To select an appropriate factors for categorical variables, a multivariate Cox regression model was built with hazard ratio (HR) values as the risk assessment parameter. $\mathrm{P}<0.05$ was considered statistically significant, and tests were 2 -sided.

\section{Results}

\section{Patient characteristics}

Eighty-seven patients with CRC who died in our hospital in the period from 1993 to 2020 were included in our study. All of the patients were aged over 80 years old, died from pathologically confirmed CRC (histopathology), and had complete clinical data. Adenocarcinoma was the most common clinical pathology among the patients. Table 1 details the clinical characteristics of the patients. In our cohort, the majority of patients had complications of the circulatory or respiratory system, with the most common complications being hypertension, coronary heart disease, diabetes, and pneumonia. Ten patients had other kinds of tumors, and $65.5 \%$ of patients had an Eastern Cooperative Oncology Group (ECOG) score of 1 when they were diagnosed (Table 1).

\section{Clinical characteristics and survival}

The overall median survival time of the patients in our cohort was 45 months. For patients with adenocarcinoma, MAC, and adenosquamous carcinoma, the median survival time was 39, 22, and 128 months, respectively (Table 2). Among the patients, the CRC was found most frequently in the right colon. The median survival time of patients with tumors in the right colon, left colon, and rectum was 22 , 57 , and 49 months, respectively (Table 2). Sex, smoking, and complications were found to have no significant effect on survival time (Table 3).

\section{Primary tumor characteristics and survival}

The effects of pathological pattern, primary site, staging, 
Table 1 Characteristics of elderly CRC patients

\begin{tabular}{|c|c|}
\hline Patient characteristics & $\mathrm{N}=87$ \\
\hline Age (years) & $80-96(85.400 \pm 3.820)$ \\
\hline \multicolumn{2}{|l|}{ Sex, n (\%) } \\
\hline Male & $62(71.3)$ \\
\hline Female & $25(28.7)$ \\
\hline \multicolumn{2}{|l|}{ Smoking, n (\%) } \\
\hline Yes & $24(27.6)$ \\
\hline No & $63(72.4)$ \\
\hline \multicolumn{2}{|l|}{ ECOG PS, n (\%) } \\
\hline 0 & 0 \\
\hline 1 & $57(65.5)$ \\
\hline 2 & $18(20.7)$ \\
\hline 3 & $12(13.8)$ \\
\hline \multicolumn{2}{|l|}{ Histology, n (\%) } \\
\hline Adenocarcinoma & 75 (86.2) \\
\hline Mucoid adenocarcinoma & $8(9.2)$ \\
\hline Adenosquamous carcinoma & $4(4.6)$ \\
\hline \multicolumn{2}{|l|}{ Tumor location } \\
\hline Colon, right side & $44(50.6)$ \\
\hline Colon, left side & $17(19.5)$ \\
\hline Rectum & $26(29.9)$ \\
\hline \multicolumn{2}{|l|}{ Cancer stage, n (\%) } \\
\hline I & $8(9.2)$ \\
\hline II & $31(35.6)$ \\
\hline III & $12(13.8)$ \\
\hline IV & $28(32.2)$ \\
\hline Unknown & $8(9.2)$ \\
\hline \multicolumn{2}{|l|}{ Comorbidity, n (\%) } \\
\hline Hypertension & 49 (56.3) \\
\hline Heart & $32(36.8)$ \\
\hline Diabetes & $20(23.0)$ \\
\hline Lung & $16(18.4)$ \\
\hline Cerebrovascular accident & $10(11.5)$ \\
\hline Chronic renal failure & $3(3.4)$ \\
\hline Any prior tumor & $10(11.5)$ \\
\hline No & $14(16.1)$ \\
\hline
\end{tabular}

Table 1 (continued)
Table 1 (continued)

\begin{tabular}{lc}
\hline Patient characteristics & $\mathrm{N}=87$ \\
\hline Primary treatment, $\mathrm{n}(\%)$ & $40(46.0)$ \\
Surgery & $17(19.5)$ \\
Surgery + adjuvant therapy & $7(8.0)$ \\
Chemotherapy and/or radiotherapy & $2(2.3)$ \\
EMR & $21(24.1)$ \\
No therapy & \\
Tumor size, $\mathrm{n}(\%)$ & $18(20.7)$ \\
$\leq 30$ mm & $25(28.7)$ \\
$\leq 50$ mm & $14(16.1)$ \\
$>50$ mm & $30(34.5)$ \\
Unknown &
\end{tabular}

and degree of differentiation on patient survival are shown in Figure 1. The pathological pattern and primary site had no significant effect on overall survival (OS) time. In our study, 8 patients $(9.2 \%)$ did not undergo staging evaluation, and $32.2 \%$ patients had stage IV disease at the time of diagnosis. The survival time of stage IV patients was significantly shorter than that of stage I patients $(\mathrm{P}=0.001)$. The effect of the degree of differentiation on survival time was also significant. Furthermore, poorly to moderately, moderately and moderately to well differentiated cancer cells were associated with a reduced risk of death compared to poorly differentiated cancer cells $(\mathrm{P}<0.05)$. Tumor size had no significant effect on OS time $(\mathrm{P}=0.010)$.

\section{Treatment and survival}

Twenty-one patients in our study received no treatment after diagnosis. Among the 66 patients who accepted treatment, the most common treatment was surgery. Forty patients accepted surgery, 17 accepted surgery and adjuvant therapy (radiotherapy, chemotherapy, or chemoradiotherapy), 7 accepted adjuvant therapy, and 2 accepted endoscopic mucosal resection (EMR). Survival analysis showed that patients who received surgery had a longer survival time than those who did not (Figure 2).

\section{Discussion}

One-third of new CRC diagnoses worldwide are in patients 
Table 2 Pathology and survival

\begin{tabular}{|c|c|c|c|c|}
\hline \multirow{2}{*}{ Tumor characteristics } & \multicolumn{4}{|c|}{ Median survival times } \\
\hline & Estimate & Std. error & Lower bound & Upper bound \\
\hline \multicolumn{5}{|l|}{ Pathology } \\
\hline Adenocarcinoma & 39.000 & 7.687 & 23.913 & 54.087 \\
\hline Adenosquamous carcinoma & 128.000 & 109.000 & 0.000 & 341.640 \\
\hline \multicolumn{5}{|l|}{ Tumor location } \\
\hline Colon, right side & 22.000 & 12.319 & 0.000 & 46.145 \\
\hline Colon, left side & 57.000 & 17.493 & 22.714 & 91.286 \\
\hline
\end{tabular}

over 75 years old (18). To date, a standard treatment for CRC in elderly patients has yet to be established (11). Previous studies have found that patients over the age of 75 years often fail to receive appropriate treatments (19). Old age should not be viewed as a reason for the patients to give up the opportunity of curable treatment such as surgery or chemotherapy. The overall physical state of elderly patients should be comprehensively assessed, and an appropriate treatment plan should be given according to the assessment results (20). At present, clinical studies of elderly patients with CRC are limited (21-23); however, the current study provides a basis for the use of surgery and adjuvant therapy in the treatment of such patients.

Patients with stage IV tumors made up the largest proportion of patients in this study. For these patients, metastases were found at the time of diagnosis. Another finding was that almost all stage II and III patients received surgery, whereas stage IV patients were more likely to receive only supportive care. Approximately one-third of the patients in our study were at an advanced stage, and they all received only supportive care. Many factors can influence treatment decision-making in elderly patients with CRC, including age, complications, the physiological function of an organ, and the opinions of the patient and their relatives. The most common reasons for elderly patients declining adjuvant chemotherapy are age, complications, a poor physical condition, or rejection by the patient or family members (24).

At present, surgery is believed to be the treatment of choice for stage I-III colon cancers and some stage IV colon cancers (25). Some studies have suggested that surgical treatment shortens the OS of elderly patients $(26,27)$, whereas others have arrived at the opposite conclusion $(28,29)$. In our study, the univariate analysis found that there was a significant difference in the survival rates of patients who did and did not receive surgical treatment, and the difference was still significant in the multivariate analysis. This observation confirmed that surgical treatment could significantly improve the survival of elderly patients with colon cancer; thus, we believe that surgery is a feasible approach to treat colon cancer, even in the elderly population (30,31). Age was the main reason for the different therapeutic approaches in young and elderly CRC patients (15). A study by Temple et al. (32) observed that primary-cancer-directed surgery (CDS) was less performed on patients older than 75 years, blacks, and those of lower socioeconomic status. There are many lines of evidence to support that most elderly people's bodies can tolerate cancer treatment and benefit from it as much as young people $(33,34)$. Although the 5 -year OS in the elderly group was lower than that in the younger group (64\% vs. $80 \%, \mathrm{P}<0.01)$, there was no difference in diseasespecific survival at 5 years between those two groups (35). A Chinese study of CRC patients aged $\geq 80$ showed that, 40 of the 186 patients died after laparoscopic or open surgery, the 3 - and 5-year OS rates were $79.6 \%$ and $63.4 \%$ in the open group and $83.9 \%$ and $73.1 \%$ in the laparoscopic group (36). However, the difference in survival may be attributable 
Table 3 Primary tumor characteristics and survival

\begin{tabular}{|c|c|c|c|c|c|c|c|}
\hline \multirow{3}{*}{ Characteristics } & \multicolumn{7}{|c|}{ Variables in the equation } \\
\hline & \multirow{2}{*}{$\beta$} & \multirow{2}{*}{ SE } & \multirow{2}{*}{ Wald $\chi^{2}$} & \multirow{2}{*}{$\mathrm{P}$} & \multirow{2}{*}{$\mathrm{HR}$} & \multicolumn{2}{|c|}{$95.0 \% \mathrm{Cl}$} \\
\hline & & & & & & Lower & Upper \\
\hline Tumor size & -0.077 & 0.103 & 0.560 & 0.454 & 0.926 & 0.757 & 1.133 \\
\hline \multicolumn{8}{|l|}{ Pathology } \\
\hline ASC (vs. A) & -1.527 & 1.501 & 1.035 & 0.309 & 0.217 & 0.011 & 4.115 \\
\hline \multicolumn{8}{|l|}{ Differentiation } \\
\hline P-M (vs. P) & -2.343 & 0.992 & 5.581 & $0.018^{\star}$ & 0.096 & 0.014 & 0.671 \\
\hline$M(v s . P)$ & -2.161 & 0.926 & 5.451 & $0.020^{\star}$ & 0.115 & 0.019 & 0.707 \\
\hline \multicolumn{8}{|l|}{ Stage } \\
\hline II (vs. I) & 0.226 & 0.757 & 0.089 & 0.765 & 1.253 & 0.284 & 5.521 \\
\hline III (vs. I) & 0.273 & 0.917 & 0.089 & 0.766 & 1.314 & 0.218 & 7.923 \\
\hline IV (vs. I) & 2.637 & 1.203 & 4.806 & $0.028^{*}$ & 13.972 & 1.322 & 147.602 \\
\hline \multicolumn{8}{|l|}{ Treatment } \\
\hline $\mathrm{C}, \mathrm{R}$, or $\mathrm{C}+\mathrm{R}$ (vs. no) & -2.221 & 1.222 & 3.305 & 0.069 & 0.108 & 0.010 & 1.189 \\
\hline S (vs. no) & -3.072 & 1.394 & 4.856 & $0.028^{*}$ & 0.046 & 0.003 & 0.712 \\
\hline $\mathrm{S}+\mathrm{C}, \mathrm{S}+\mathrm{R}$, or $\mathrm{S}+\mathrm{C}+\mathrm{R}$ (vs. no) & -3.739 & 1.981 & 3.561 & 0.059 & 0.024 & 0.000 & 1.155 \\
\hline
\end{tabular}

$\mathrm{Cl}$, confidence interval; $\mathrm{A}$, adenocarcinoma; MA, mucoid adenocarcinoma; ASC, adenosquamous carcinoma; P, poorly; M, moderately; W, well; C, chemotherapy; R, radiotherapy; S, surgery; EMR, endoscopic mucosal resection; CVA, cerebrovascular accident. *, P<0.05.

to reasons other than the presence or absence of surgery, such as perioperative care and postoperative nutritional support. Without information such as the quality of surgery, postoperative complications, and perioperative care, residual confounding by unmeasured factors cannot be ruled out.

After including combinations of chemotherapy, radiotherapy, and different treatment regimens into the multivariate analysis, we found that treatment combining surgery with chemotherapy or radiotherapy had no significant effect on the survival time of patients. From this, it can be inferred that uncertainty surrounds whether or not elderly patients can benefit from chemotherapy or radiotherapy. Adjuvant chemotherapy has clearly been shown to reduce the risks of disease recurrence and death in colon cancer patients with lymph node metastasis. However, the role of adjuvant therapy in treating patients with stage II colon cancer and elderly patients remains controversial (37). Some investigators believe that adjuvant therapy should be recommended for patients with stage III colon cancer to reduce recurrence and improve survival (38-40), but other studies have reached completely opposite conclusions. For instance, in the study of Vermeer, no clear linear pattern was observed between a higher proportion of adjuvant chemotherapy and better relative survival (41). A recently published phase III trial assessed the efficacy of 5-fluorouracil/folic acid (or levamisole) combined with adjuvant therapy in 3,239 patients with CRC versus an observation group. The study showed that the proportional 
A

Pathology

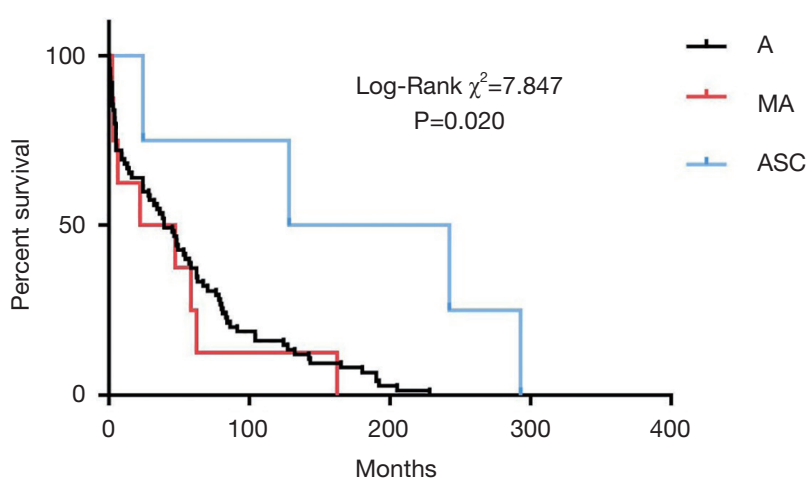

C

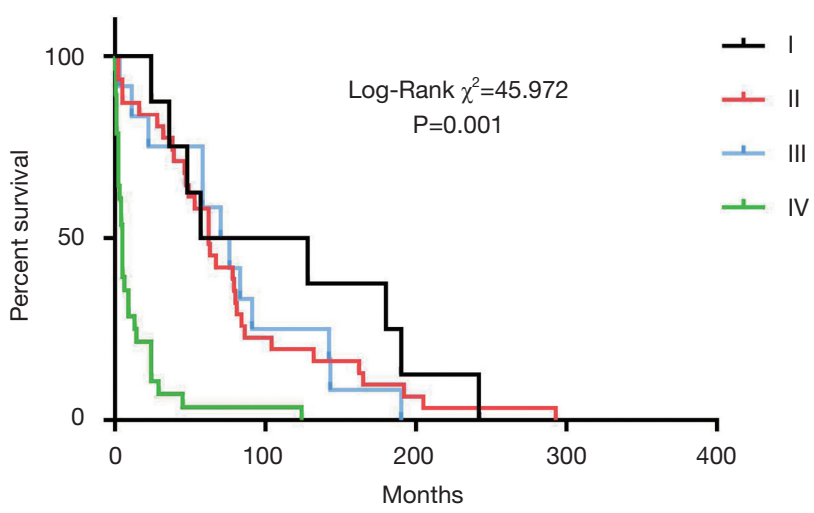

B

Tumor location

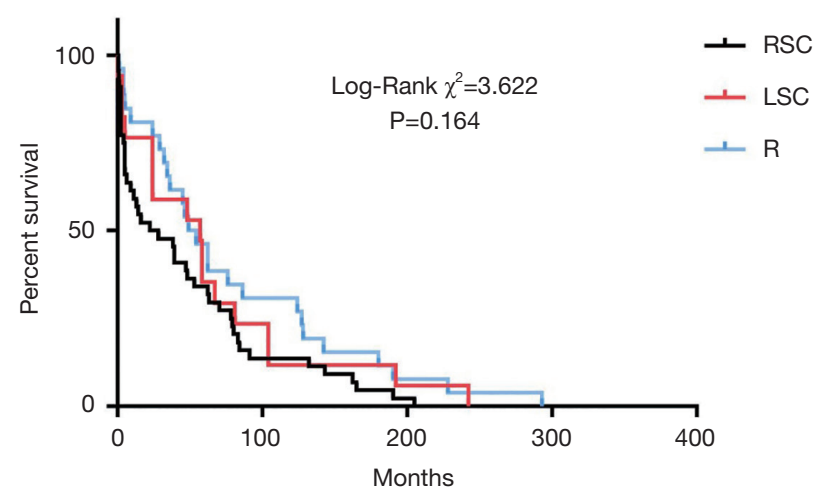

D Differentiation degree

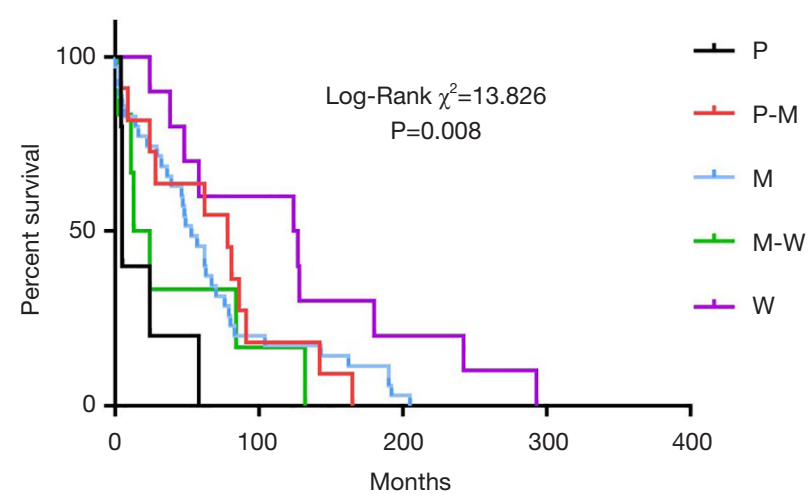

Figure 1 Primary tumor characteristics and survival. (A) Pathological pattern and survival: A, adenocarcinoma; MA, mucoid adenocarcinoma; ASC, adenosquamous carcinoma; (B) Tumor location and survival: RSC, right-sided colon; LSC, left-sided colon; R, rectum; (C) Tumor stage and survival: I, stage I; II, stage II; III, stage III; IV, stage IV; (D) Differentiation degree and survival: P, poorly; M, moderately; $W$, well.

reduction in mortality with chemotherapy is less for older patients (42). In our study cohort, chemotherapy also failed to show a significant effect on the survival of elderly patients. For the reasons described above, many elderly people find it difficult to tolerate a full course of chemotherapy or radiotherapy because of the functional deterioration of multiple organs including the liver, kidney, and hematologic system (43), which results in low-quality chemotherapy and the poor adherence of some patients. Therefore, our study concluded that for elderly patients, evidence of the benefit of chemotherapy is extremely limited. Thus, caution should be exercised in using chemotherapy to treat these patients, and this treatment should not be a routine recommendation. More relevant studies are needed in the future to provide higher quality supplementary evidence at the evidence-based medical level.

Radiotherapy is one of the best treatment modalities for rectal cancer $(44,45)$. A study of 85,934 patients with stage III colon cancer showed that elderly patients could benefit from radiation therapy, although they were less likely to receive this treatment than young adults were (46). Furthermore, in a population-based study, adjuvant radiotherapy did not negatively affect the quality of life of elderly patients with colon cancer (47). The European Organization for Research and Treatment of Cancer (EORTC) Elderly Task Force has suggested that elderly patients with stage III disease should not refuse adjuvant radiotherapy on the basis of their age alone, and radiotherapy should not be rejected for this reason either (48). Treatment decisions should be made after 


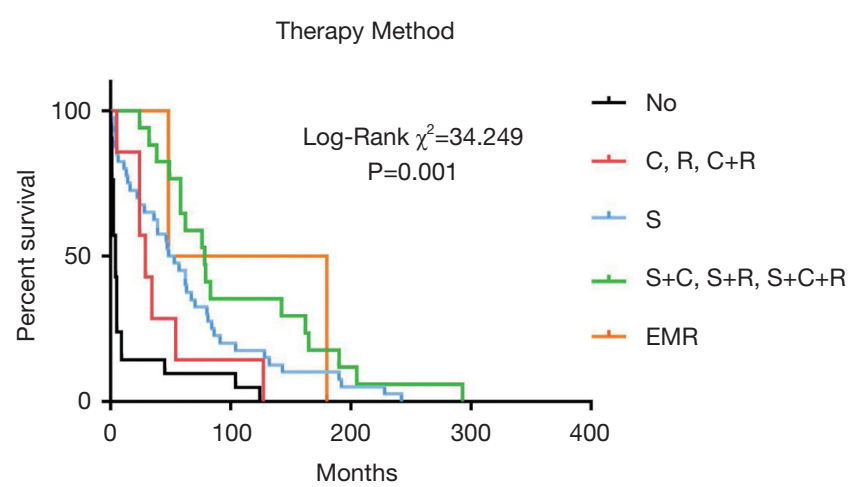

Figure 2 Treatment and survival. C, chemotherapy; R, radiotherapy; $\mathrm{S}$, surgery; EMR, endoscopic mucosal resection.

consideration of the estimated absolute benefit, life expectancy, treatment tolerance, cognition, comorbidities, and preference of the patient. The HERBERT study showed that for elderly patients with rectal cancer, radiation therapy can provide a good tumor response, although it carries considerable risk of toxicity. The potential benefits and risks of high-dose rate endorectal brachytherapy compared to external beam radiotherapy (EBRT) must be further assessed (49). In our study, radiotherapy had no significant effect on the survival of patients, which may be attributable to most patients failing to complete a sufficient number of radiotherapy courses in a standardized manner, or the dose selected being too low considering the age factor, thus resulting in failure to produce a significant benefit. However, radiotherapy did not show a negative effect on our study subjects either, so its therapeutic significance for elderly patients cannot be ruled out.

The majority of CRC are adenocarcinomas (96\%), which in some cases exhibit a mucinous component (50). The differentiation of colon tumors is an independent risk factor for cancer prognosis. Some studies have also suggested that the degree of differentiation is associated with the risk of lymph node metastasis (51), and is an extremely important prognostic indicator. The results of this study showed that the OS time in patients with poorly differentiated disease was short. Therefore, paying attention to the findings of pathological biopsy is especially important for evaluating the prognosis of cancer patients.

Limitations of this study include its small sample size. Because this study was retrospective, we excluded patients with hereditary CRC. However, family history in some patients might have overlooked. Also, since this study is a retrospective analysis, the absence of some indicators may have affected the results. However, to minimize bias, we selected data from deceased patients.

In summary, the treatment outcomes of CRC patients aged 80 years old and above were retrospectively analyzed. The right colon was the most common site of the primary lesion in our patients, most of whom were at an advanced disease stage. These features are consistent with those often observed in elderly patients with CRC (13). Also, among the patients in this study, adenocarcinoma was the most common pathology, and poorly differentiated cancers were associated with a short survival time. Surgery was found to be the best treatment for CRC. Overall, our study shows that individualized evaluation and appropriate treatment should be provided for CRC patients aged 80 years and above.

\section{Acknowledgments}

Funding: None.

\section{Footnote}

Reporting Checklist: The authors have completed the STROBE reporting checklist. Available at http://dx.doi. org/10.21037/jgo-21-63

Data Sharing Statement: Available at http://dx.doi. org/10.21037/jgo-21-63

Conflicts of Interest: All authors have completed the ICMJE uniform disclosure form (available at http://dx.doi. org/10.21037/jgo-21-63). The authors have no conflicts of interest to declare.

Ethical Statement: The authors are accountable for all aspects of the work in ensuring that questions related to the accuracy or integrity of any part of the work are appropriately investigated and resolved. The study was approved by the PLA General Hospital Medical Ethics Committee (No. S2020-447-01). All procedures performed in this study involving human participants were in accordance with the Declaration of Helsinki (as revised in 2013). Individual consent for this retrospective analysis was waived.

Open Access Statement: This is an Open Access article distributed in accordance with the Creative Commons Attribution-NonCommercial-NoDerivs 4.0 International 
License (CC BY-NC-ND 4.0), which permits the noncommercial replication and distribution of the article with the strict proviso that no changes or edits are made and the original work is properly cited (including links to both the formal publication through the relevant DOI and the license). See: https://creativecommons.org/licenses/by-nc-nd/4.0/.

\section{References}

1. Sharpless NE. COVID-19 and cancer. Science 2020;368:1290.

2. Balzora S, Issaka RB, Anyane-Yeboa A, et al. Impact of COVID-19 on colorectal cancer disparities and the way forward. Gastrointest Endosc 2020;92:946-50.

3. Del Vecchio Blanco G, Calabrese E, Biancone L, et al. The impact of COVID-19 pandemic in the colorectal cancer prevention. Int J Colorectal Dis 2020;35:1951-4.

4. Maringe C, Spicer J, Morris M, et al. The impact of the COVID-19 pandemic on cancer deaths due to delays in diagnosis in England, UK: a national, population-based, modelling study. Lancet Oncol 2020;21:1023-34.

5. Dinmohamed AG, Cellamare M, Visser O, et al. The impact of the temporary suspension of national cancer screening programmes due to the COVID-19 epidemic on the diagnosis of breast and colorectal cancer in the Netherlands. J Hematol Oncol 2020;13:147.

6. Siegel R, Desantis C, Jemal A. Colorectal cancer statistics, 2014. CA Cancer J Clin 2014;64:104-17.

7. Araghi M, Soerjomataram I, Jenkins M, et al. Global trends in colorectal cancer mortality: projections to the year 2035. Int J Cancer 2019;144:2992-3000.

8. Arnold M, Sierra MS, Laversanne M, et al. Global patterns and trends in colorectal cancer incidence and mortality. Gut 2017;66:683-91.

9. Zhou M, Wang H, Zeng X, et al. Mortality, morbidity, and risk factors in China and its provinces, 1990-2017: a systematic analysis for the Global Burden of Disease Study 2017. Lancet 2019;394:1145-58.

10. Mauri G, Sartore-Bianchi A, Russo AG, et al. Earlyonset colorectal cancer in young individuals. Mol Oncol 2019;13:109-31.

11. Itatani $Y$, Kawada K, Sakai Y. Treatment of Elderly Patients with Colorectal Cancer. Biomed Res Int 2018;2018:2176056.

12. Jafari MD, Jafari F, Halabi WJ, et al. Colorectal Cancer Resections in the Aging US Population: A Trend Toward Decreasing Rates and Improved Outcomes. JAMA Surg
2014;149:557-64.

13. Arai T, Takubo K. Clinicopathological and molecular characteristics of gastric and colorectal carcinomas in the elderly. Pathol Int 2007;57:303-14.

14. Kotake K, Asano M, Ozawa H, et al. Tumour characteristics, treatment patterns and survival of patients aged 80 years or older with colorectal cancer. Colorectal Dis 2015;17:205-15.

15. Serra-Rexach JA, Jimenez AB, García-Alhambra MA, et al. Differences in the therapeutic approach to colorectal cancer in young and elderly patients. Oncologist 2012;17:1277-85.

16. Dekker E, Tanis PJ, Vleugels JLA, et al. Colorectal cancer. Lancet 2019;394:1467-80.

17. Brierley, JD, Gospodarowicz, MK, Wittekind, C. TNM classification of malignant tumours. 8th ed. John Wiley \& Sons, Ltd. 2017.

18. Institute NC. SEER Stat Fact Sheets: Colon and Rectum Cancer. Available online: https://seer.cancer.gov/statfacts/ html/ colorect.html. Accessed January 2021.

19. Yamano T, Yamauchi S, Kimura K, et al. Influence of age and comorbidity on prognosis and application of adjuvant chemotherapy in elderly Japanese patients with colorectal cancer: A retrospective multicentre study. Eur J Cancer 2017;81:90-101.

20. Kim JH. Chemotherapy for colorectal cancer in the elderly. World J Gastroenterol 2015;21:5158-66.

21. Cunningham D, Lang I, Marcuello E, et al. Bevacizumab plus capecitabine versus capecitabine alone in elderly patients with previously untreated metastatic colorectal cancer (AVEX): an open-label, randomised phase 3 trial. Lancet Oncol 2013;14:1077-85.

22. Shigeta K, Baba H, Yamafuji K, et al. Effects of laparoscopic surgery on the patterns of death in elderly colorectal cancer patients: competing risk analysis compared with open surgery. Surg Today 2016;46:422-9.

23. Fujii S, Ishibe A, Ota $M$, et al. Long-term results of a randomized study comparing open surgery and laparoscopic surgery in elderly colorectal cancer patients (Eld Lap study). Surg Endosc 2020. [Epub ahead of print]. doi: 10.1007/s00464-020-08026-0.

24. Hoeben KW, van Steenbergen LN, van de Wouw AJ, et al. Treatment and complications in elderly stage III colon cancer patients in the Netherlands. Ann Oncol 2013;24:974-9.

25. Pallis AG, Papamichael D, Audisio R, et al. EORTC Elderly Task Force experts' opinion for the treatment 
of colon cancer in older patients. Cancer Treat Rev 2010;36:83-90.

26. Surgery for colorectal cancer in elderly patients: a systematic review. Colorectal Cancer Collaborative Group. Lancet 2000;356:968-74.

27. van Leeuwen BL, Påhlman L, Gunnarsson U, et al. The effect of age and gender on outcome after treatment for colon carcinoma. A population-based study in the Uppsala and Stockholm region. Crit Rev Oncol Hematol 2008;67:229-36.

28. Chiappa A, Zbar AP, Bertani E, et al. Surgical treatment of advanced colorectal cancer in the elderly. Chir Ital 2005;57:589-96.

29. Quaglia A, Capocaccia R, Micheli A, et al. A wide difference in cancer survival between middle aged and elderly patients in Europe. Int J Cancer 2007;120:2196-201.

30. Jung YH, Kim JY, Jang YN, et al. Clinical characteristics and treatment propensity in elderly patients aged over 80 years with colorectal cancer. Korean J Intern Med 2018;33:1182-93.

31. Ong ES, Alassas M, Dunn KB, et al. Colorectal cancer surgery in the elderly: acceptable morbidity? Am J Surg 2008;195:344-8.

32. Temple LK, Hsieh L, Wong WD, Saltz L, Schrag D. Use of surgery among elderly patients with stage IV colorectal cancer. J Clin Oncol 2004;22:3475-84.

33. Devoto L, Celentano V, Cohen R, et al. Colorectal cancer surgery in the very elderly patient: a systematic review of laparoscopic versus open colorectal resection. Int J Colorectal Dis 2017;32:1237-42.

34. Vacante M, Cristaldi E, Basile F, et al. Surgical approach and geriatric evaluation for elderly patients with colorectal cancer. Updates Surg 2019;71:411-7.

35. Ueda Y, Shiraishi N, Kawasaki T, et al. Short- and longterm outcomes of laparoscopic surgery for colorectal cancer in the elderly aged over 80 years old versus nonelderly: a retrospective cohort study. BMC Geriatr 2020;20:445.

36. Zhou S, Wang X, Zhao C, et al. Laparoscopic vs open colorectal cancer surgery in elderly patients: short- and long-term outcomes and predictors for overall and diseasefree survival. BMC Surg 2019;19:137.

37. Pallis AG, Mouzas IA. Adjuvant chemotherapy for colon cancer. Anticancer Res 2006;26:4809-15.

38. Schmoll HJ, Van Cutsem E, Stein A, et al. ESMO Consensus Guidelines for management of patients with colon and rectal cancer. a personalized approach to clinical decision making. Ann Oncol 2012;23:2479-516.

39. Schmoll HJ, Twelves C, Sun W, et al. Effect of adjuvant capecitabine or fluorouracil, with or without oxaliplatin, on survival outcomes in stage III colon cancer and the effect of oxaliplatin on post-relapse survival: a pooled analysis of individual patient data from four randomised controlled trials. Lancet Oncol 2014;15:1481-92.

40. Breugom AJ, Bastiaannet E, Boelens PG, et al. Adjuvant chemotherapy and relative survival of patients with stage II colon cancer - A EURECCA international comparison between the Netherlands, Denmark, Sweden, England, Ireland, Belgium, and Lithuania. Eur J Cancer 2016;63:110-7.

41. Vermeer NCA, Claassen YHM, Derks MGM, et al. Treatment and Survival of Patients with Colon Cancer Aged 80 Years and Older: A EURECCA International Comparison. Oncologist 2018;23:982-90.

42. Quasar Collaborative Group, Gray R, Barnwell J, et al. Adjuvant chemotherapy versus observation in patients with colorectal cancer: a randomised study. Lancet 2007;370:2020-9.

43. Reese ES, Onukwugha E, Hanna N, et al. Clinical and demographic characteristics associated with the receipt of chemotherapy treatment among 7951 elderly metastatic colon cancer patients. Cancer Med 2013;2:907-15.

44. Glynne-Jones R, Hall M. Radiotherapy and locally advanced rectal cancer. Br J Surg 2015;102:1443-5.

45. Maingon P, Huguet F. Rectal Cancer: The Radiation Oncologist: The Great Watchmaker. Semin Radiat Oncol 2016;26:173-5.

46. Jessup JM, Stewart A, Greene FL, et al. Adjuvant chemotherapy for stage III colon cancer: implications of race/ethnicity, age, and differentiation. JAMA 2005;294:2703-11.

47. Bouvier AM, Jooste V, Bonnetain F, et al. Adjuvant treatments do not alter the quality of life in elderly patients with colorectal cancer: a population-based study. Cancer 2008;113:879-86.

48. Pallis AG, Papamichael D, Audisio R, et al. EORTC Elderly Task Force experts' opinion for the treatment of colon cancer in older patients. Cancer Treat Rev 2010;36:83-90.

49. Rijkmans EC, van Triest B, Nout RA, et al. Evaluation of clinical and endoscopic toxicity after external beam radiotherapy and endorectal brachytherapy in elderly patients with rectal cancer treated in the HERBERT study. Radiother Oncol 2018;126:417-23. 
50. Ponz de Leon M, Di Gregorio C. Pathology of colorectal cancer. Dig Liver Dis 2001;33:372-88.

51. Derwinger K, Kodeda K, Bexe-Lindskog E, et al. Tumour differentiation grade is associated with TNM staging and

Cite this article as: Shen L, Meng K, Wang Y, Yu X, Wang P, Zhang $\mathrm{X}$. The clinical features, management, and survival of elderly patients with colorectal cancer. J Gastrointest Oncol 2021;12(1):89-99. doi: 10.21037/jgo-21-63 the risk of node metastasis in colorectal cancer. Acta Oncol 2010;49:57-62.

(English Language Editor: J. Reynolds) 